\title{
Analysis of Soybean Supply Fluctuations and Its Influencing Factors------A Case Study in Jilin Province
}

\author{
Chenxi Li ${ }^{1, a}$, Shuai $\mathrm{Liu}^{1, \mathrm{~b}}$ and Wenming $\mathrm{Liu}^{2, \mathrm{C}}$ \\ ${ }^{1}$ School of economics and management, Jilin Agricultural University, No. 2888, Xin Cheng street, \\ Changchun, Jilin, 130118 \\ ${ }^{2}$ Institute of Agricultural Economics and information, Jilin Academy of Agricultural Sciences, No. \\ 1363, Eco Street, Changchun, Jilin, 130118

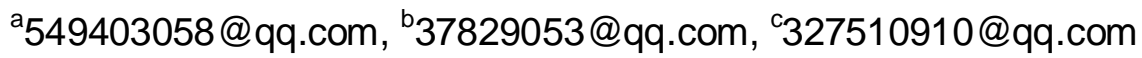

Keywords: Soybean; Supply quantity; Influencing factors; Jilin province

\begin{abstract}
Jilin is an important commodity grain base in China, meanwhile, it is also one of the 13 main grain producing provinces; and, the soybean planting area in Jilin has been always ranked in the forefront of China. Soybean is one of the most important food crops in China, as well as an important industrial raw material. With the development of China's economy, the domestic market demand for soybean increases year by year, resulting in the increased demand exceeding supply. In this study, the soybean supply fluctuation in Jilin province was taken as subject investigated, and on the basis of using statistical analysis method and Stata software, analysis on soybean supply fluctuation and its influencing factors in Jilin Province from 1998-2014 was conducted, results showed that: The fluctuation of both soybean supply and the soybean planting area was strong. In recent years, soybean market prices, production costs had shown an increasing trend. From the angle of influencing factors, the regression results showed that there was a positive correlation between soybean sown area, previous soybean price, labor costs, machinery costs, and soybean supply; and there was a negative correlation between seed costs, production costs, fertilizer costs, pesticide costs, and soybean supply, such influencing factors were analyzed to explore effective ways to increase soybean yield in Jilin Province, increase the income of farmers, ensure effective supply and promote the reform of agricultural supply side.
\end{abstract}

\section{Introduction}

The natural environment of Jilin is suitable for soybean cultivation and the soil is fertile, thus, it is called "the hometown of soybean" ${ }^{[1]}$. With the rapid development of industrialization, the domestic demand for soybean shows rapid growth, but the total soybean yield can only reach $1 / 3$ the demand, resulting in a large quantity of imported soybean in China ${ }^{[2]}$. In 1990s, China turned to be a soybean net importer from the original soybean producing and exporting country. Currently, China has become the world's largest importer of soybeans, soybean has become China's largest imports of agricultural products, and the related trade accounts for $70 \%$ of the world ${ }^{[3]}$.

From the point of view of foreign countries, as soybean has an important position in agricultural production in western countries, thus, foreign scholars are very concerned about Soybean Research ${ }^{[4]}$. And in recent years, large quantities have been imported in China, therefore, most of the researches of scholars focus on the impact of soybean imports on domestic production. What's more, from the domestic point of view, the issue of food has always been a kind of social problem highly concerned by the state and the government. In 2017, the focus of Central No.1 Document is still on structural reform of agricultural supply side, and the seed supply side reform is crucial, the demand on the increased soybean production has been put on the agenda. Therefore, many scholars have focused their study on the problem of grain, however, there are few articles on soybean research, especially the research on Soybean production in Jilin Province ${ }^{[5]}$.

Compared with other grain crops or compared with other main producing areas, soybean in Jilin has its certain advantages, however, in recent years, the soybean supply fluctuation has brought greater impact on the agricultural products consumption of residents, agricultural trade, food prices 
and food security ${ }^{[6]}$. Hence, it is extreme necessary to increase domestic supply and increase soybean production while solving soybean supply and demand gap, and increasing imports. The study of soybean supply fluctuation and its influencing factors has an important effect on increasing soybean yield and increasing farmers' income ${ }^{[7]}$, meanwhile, it also has very important significance on adjusting the structure of grain crops, promoting structural reform of agricultural supply side, and solving the problems of agriculture, countryside and farmers.

\section{Present Situation of Soybean Supply in Jilin}

Large Fluctuation in Jilin Soybean Supply. Since entering the new century, the supply of soybean in Jilin presented a rapid expansion ${ }^{[8]}$ (Fig. 1), the supply had increased from 636 thousand tons in 1999 to about $\$ 1$ million 203 thousand in 2000, except for slight decrease in 2001, it had been on the rise all the time to 2004, 2004 reached a maximum of 1 million 520 thousand and 600 tons, showing an average annual increase of more than 636 thousand tons in 1999, up to $19.05 \%$. Therefrom, soybean had become an increasingly important part of food consumption in Jilin Province ${ }^{[9]}$. However, the soybean supply began to show a downward trend in 2005, in 2005, Jilin soybean supply was 1 million 302 thousand tons, it fell to 780 thousand tons in 2007, compared with 2004, dropped 740 thousand and 600 tons, with an average annual decline of $15.06 \%$, showing significant decrease. Although a slight increase in 2008, the supply floated up and down in the level of 850 thousand tons. In 2012, the supply of soybean in Jilin declined sharply, and in 2014, the supply was only 374 thousand tons. Obviously, the supply of soybean in Jilin province fluctuated greatly from 1998-2014, especially after 2004, the quantity of supply was less.

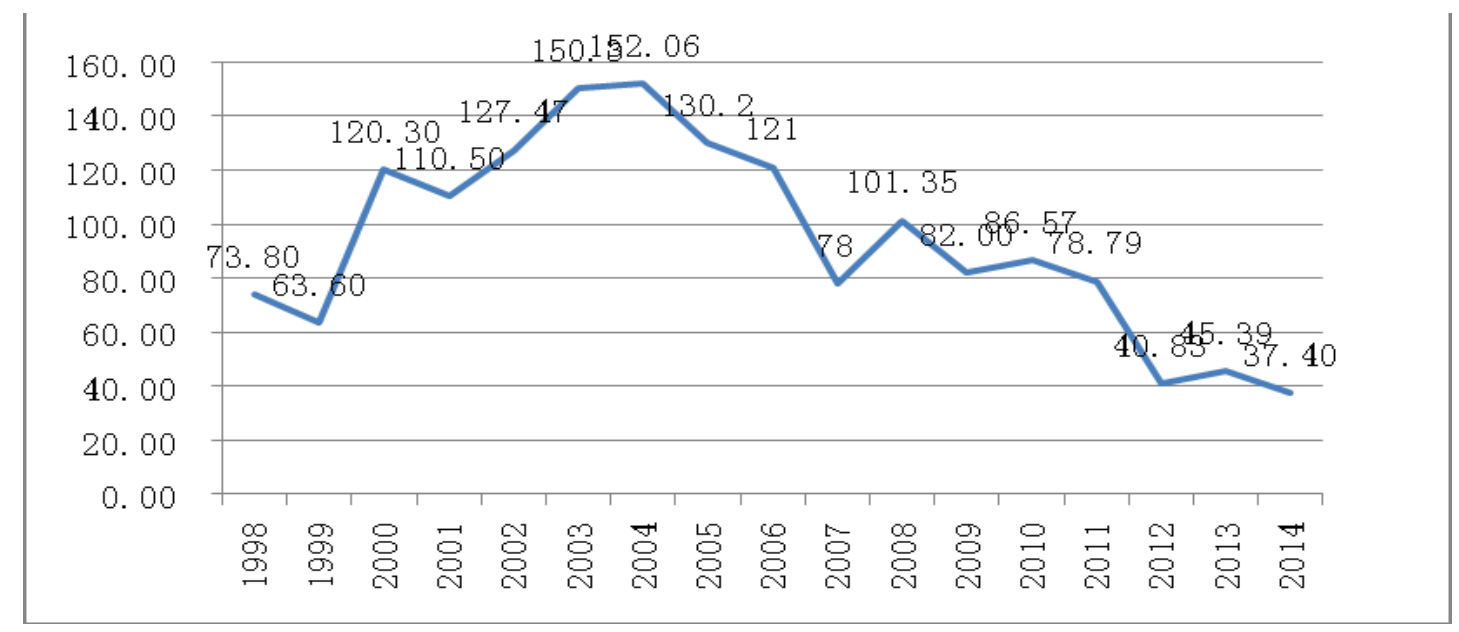

Figure 1. Fluctuation of soybean supply in Jilin from 1998-2014(million tons)

Strong Fluctuation in Soybean Sowing Area in Jilin. Jilin province is a big province of grain production in China, as well as major soybean producing area ${ }^{[10]}$. In 1998, and 1999, the soybean sowing area was around 300 thousand hectares, and starting from 2000, the soybean sowing area in Jilin showed rapid expansion trend (Fig. 2), increasing from 278 thousand and 300 hectares in 1999 reached to 538 thousand and 900 hectares in 2000, an increase of 260 thousand and 600 hectares. From 2001, the sowing area began to fall into an undulation period, while the overall increase was not large. From 2005, the sowing area gradually showed a downward trend, while after a decrease of 355 thousand and 900 hectares in 2007, it increased slightly, and in 2009, 437 thousand and 400 hectares increased; however, a substantial decline appeared in 2010, it has been showing a downward trend till now; in 2014, the soybean sowing area in Jilin was only 213 thousand and 600 hectares, which was also the lowest in nearly 17 years. Visibly, the soybean planting area in Jilin province has strong fluctuation and obvious decreasing trend. 


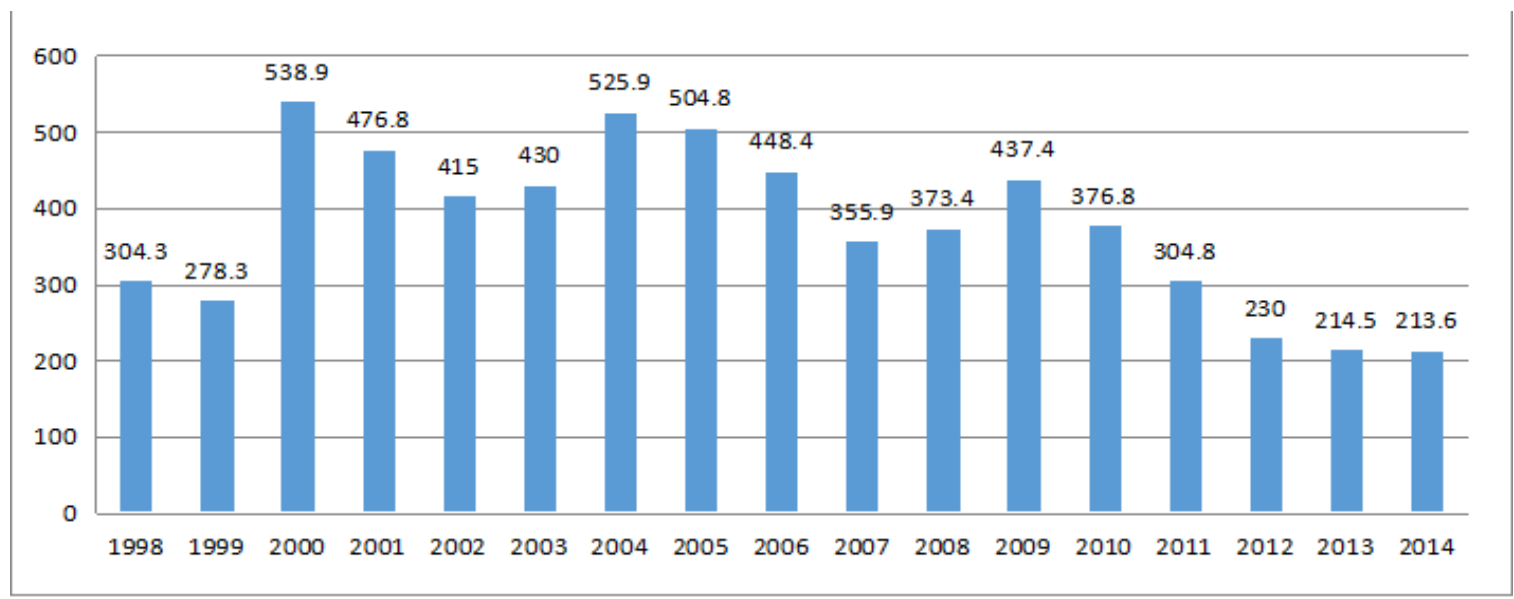

Figure 2. Fluctuation soybean sowing area in Jilin from 1998-2014(hectares)

Increasing Soybean Production Cost. Soybean production inputs include arable land, labor and capital, as well as some other factors: material and service costs, labor costs, family employment trade-in, employee costs, land costs, etc. ${ }^{[11]}$, and partial cash costs, including seed fees, fertilizer costs, pesticide fees, plastic sheeting costs, drainage $\&$ irrigation fees, machinery operation costs and fuel costs, etc. The fluctuation situation on the production cost of soybean per $50 \mathrm{~kg}$ in Jilin from 1998-2014 was shown in Fig. 3, it can be seen that the overall production costs showed an upward trend with the increase of the years, the progress of science and technology, and in recent years, the rate of increase was particularly large. In 1998, the production cost of per $50 \mathrm{~kg}$ soybean was 47.62 yuan, while in 2014; it increased to 160.33 yuan, with average annual growth of $7.88 \%$. Especially since twenty-first Century, soybean production costs increased significantly. As production cost directly affects the economic benefits of soybean, if the magnitude of fluctuation in production costs is greater than the magnitude of fluctuation in income, it will lead to decline in revenue, conversely, the revenue will rise; With the development of our national economy, the inflation is caused, and the prices of most commodities are rising, the same goes for soybean production, therefore, the inevitable increase in the overall cost of production increases, which directly affects the volatility of soybean prices $^{[12]}$.

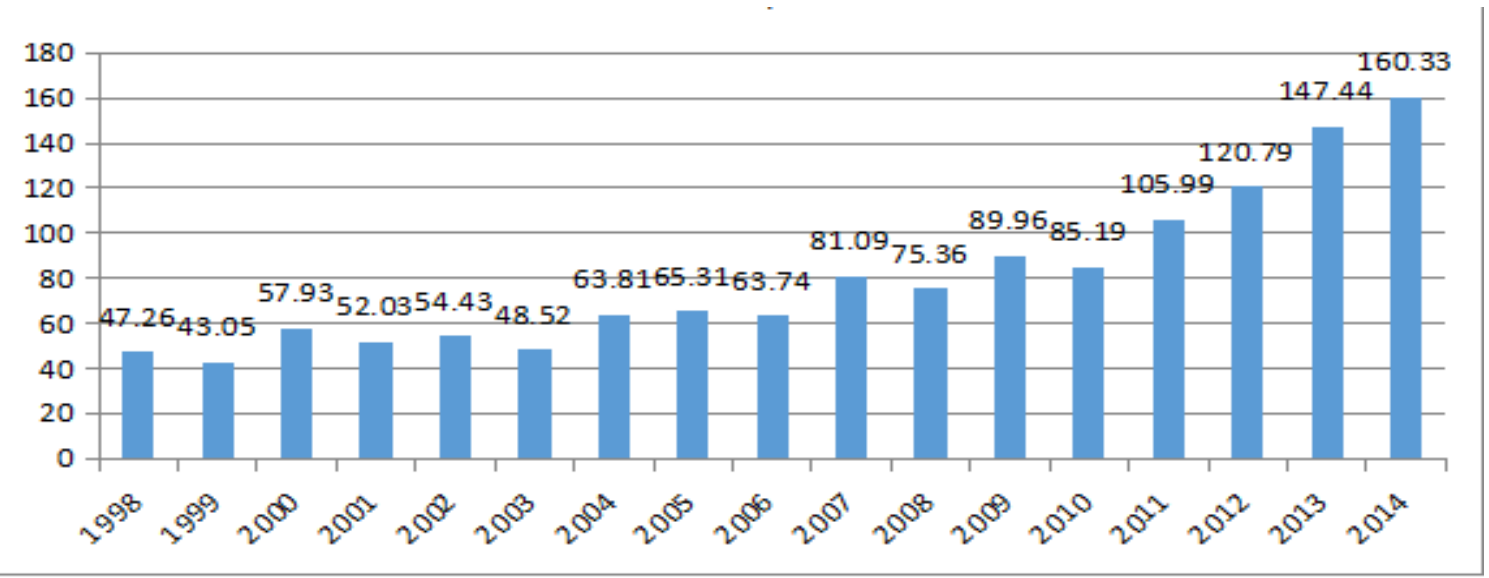

Figure 3. Fluctuation situation on the production cost of soybean per $50 \mathrm{~kg}$ in Jilin from 1998-2014 (yuan) 


\section{Model Building and Data Sources}

Variable Declaration. Soybean supply is comprehensively affected by many factors, in order to avoid missing important explanatory variables, and make comprehensive choice of explanatory variables, based on the theoretical analysis of the main factors affecting the supply of soybean in Jilin, a multiple linear regression model is set up; meanwhile, factors influencing soybean supply in Jilin are selected, and the other non-quantifiable factors are fitted to the model in the way of random disturbance term ${ }^{[13]}$. And, the following explanatory variables are introduced: area for soybean sown area, price 1 is expected price, expressed by the soybean price per $50 \mathrm{~kg}$ of previous period, seed is seed cost per acre, cost is the production cost of per $50 \mathrm{~kg}$ soybean, fertilizer is fertilizer cost per acre, medicine is the pesticide fee per acre, machine is the machinery cost per acre, labor is labor cost per acre, and $\mathrm{u}_{\mathrm{t}}$ is random disturbance term, which is used to indicate the factors which are not quantifiable and have little influence on the supply factors, for example, production technology, management level, climate and so on.

Model Construction and Data Selection. In this paper, data in Jilin statistical yearbook from 1998 to 2014 are selected, and the mathematical model of the multiple linear regression model is constructed as follow ${ }^{[14]}$ from the supply perspective:

$$
\mathrm{Y}_{1}=\beta_{1}+\beta_{2} \text { area }+\beta_{3} \text { price } 1+\beta_{4} \text { seed }+\beta_{5} \cos t+\beta_{6} \text { fertilizer }+\beta_{7} \text { medicine }+\beta_{8} \text { machine }+\beta_{9} \text { labor }+u_{\mathrm{t}}
$$

Where, $\mathrm{Y}$ is the supply of soybean in Jilin, $\beta_{1}$ is constant term, and $\beta_{\mathrm{k}}(\mathrm{k}=1-9)$ respectively represent the regression coefficient of each influencing factor, that is, the Jilin soybean supply fluctuation of each variable in all independent variables ${ }^{[15]}$.

\section{Analysis on Regression Results and Influencing Factors}

Regression Analysis Results. It is assumed that both the model and the stochastic perturbation term satisfy each classical assumptions ${ }^{[16]}$, using OLS method to estimate its parameters, and by Stata12.0 software, the regression results obtained are as follows (table 1).

Table 1 results of regression analysis

\begin{tabular}{|c|c|c|c|c|c|c|c|}
\hline Source & SS & $d f$ & \multicolumn{2}{|r|}{ MS } & & $\begin{array}{l}\text { Number of obs } \\
\text { F }(8,\end{array}$ & \multirow{2}{*}{$\begin{array}{r}17 \\
9.88 \\
0.0020\end{array}$} \\
\hline Model & 19187.6343 & 8 & \multicolumn{2}{|c|}{2398.45429} & & Prob $>F$ & \\
\hline Residual & 1942.80921 & 8 & \multicolumn{2}{|c|}{242.851151} & & \multirow{2}{*}{$\begin{array}{l}\text { R-squared } \\
\text { Adj R-squared } \\
\text { Root MSE }\end{array}$} & 0.9081 \\
\hline Total & 21130.4435 & 16 & 132 & 65272 & & & 15.584 \\
\hline Y & Coef. & std. & Err. & t & $P>|t|$ & [95\% Conf. & Interval] \\
\hline area & .2828447 & .0603 & 914 & 4.68 & 0.002 & .143582 & .4221075 \\
\hline price1 & .9409983 & .5040 & 653 & 1.87 & 0.099 & -.2213783 & 2.103375 \\
\hline seed & -4.504111 & 2.918 & 139 & -1.54 & 0.161 & -11.23335 & 2.22513 \\
\hline cost & -1.341118 & .8181 & 685 & -1.64 & 0.140 & -3.227818 & .545582 \\
\hline fertilizer & -.807112 & 1.09 & 746 & -0.74 & 0.483 & -3.338519 & 1.724295 \\
\hline medicine & -1.14939 & 2.32 & 404 & -0.49 & 0.634 & -6.508636 & 4.209856 \\
\hline machine & .3860662 & .9968 & 593 & 0.39 & 0.709 & -1.912695 & 2.684828 \\
\hline labor & .5047346 & .2876 & 415 & 1.75 & 0.117 & -.1585678 & 1.168037 \\
\hline _cons & 49.84291 & 49.1 & 649 & 1.01 & 0.341 & -63.6044 & 163.2902 \\
\hline
\end{tabular}

The regression equation obtained by regression analysis:

\footnotetext{
$\mathrm{Y}=0.283$ area +0.941 price $1-4.504$ seed -1.341 cost -0.807 fertilizer -1.149 medicine +0.3861 machine +0.505 labor +49.843
} 
Analysis on Influencing Factors of Soybean Supply in Jilin. According to the regression results of equation, $\mathrm{R}^{2}$ is 0.9081 , which means the goodness of fit of the equation is better, and the explanatory power of this equation is $91 \%$. From the equation, there is a positive correlation between soybean planting area, soybean price, labor cost, mechanical cost and the soybean supply, and the regression coefficients of seed cost, production costs, pesticide costs are large; that is, there is a negative correlation between the seed cost, production cost, chemical fertilizer cost, pesticide cost, and the soybean supply. Where, when the other conditions remain unchanged, the soybean supply will be reduced by 4.504 units if seed cost increased by 1 Unit, and the soybean supply will be reduced by 1.341 units if production costs increased by 1 unit, meanwhile, the soybean supply will be reduced by 0.807 units if fertilizer costs increased by 1 unit, what's more, the soybean supply will be reduced by 1.149 unit if pesticide costs increased by 1 unit. However, the sown area, the expected price, the mechanical cost is proportional to the supply of soybean, when the planting area increased by 1 unit, soybean supply will increase by 0.283 units; when expected price increased by 1 unit, soybean supply will increase by 0.941 units; when machinery costs increased by 1 Unit, soybean supply will increase by 0.386 units; and, when labor costs increased by 1 Unit, the soybean supply will increase by 0.505 units.

\section{Policy Suggestions}

Government Actively Guiding and Strengthening Policy Support. From 2000, the crop rotation project of "corn-soybean" was implemented in Jilin, and subsidies for growing superior grain cultivators were made to quality varieties. On the one hand, the government should further expand the scope of subsidies for soybean production, increase the intensity of subsidies, ensure the economic benefits of soybean planting, and increase the income of farmers, so as to mobilize the enthusiasm of farmers to grow soybeans. On the other hand, the government should strengthen the support to soybean processing enterprises, guide to carry out deep processing of soybean, and support the production and sales cooperation organization established by farmers.

Reasonable Determination on Target Price. In the beginning of 2014, the central government proposed the Pilot work on target price subsidy for Northeast Soybean. Therefore, it is the key point to perfect soybean target price policy, reasonably determine the target price, and stable farmers' income expectation to ensure soybean production, as well as an inevitable choice to promote the structural reform of agricultural supply side. The key point of the structural reform of supply-side is to adjust and optimize planting structure, that is, the non-dominant corn area can be down regulated for replanting soybean, and guide funds, technology to soybean planting areas, adopt measures suiting local conditions.

Breeding New Varieties and Techniques Suitable for Jilin Province. It is very important to select high yielding variety to improve the yield of soybean in Jilin province. Therefore, it is necessary to make targeted breeding on new soybean varieties suitable for Jilin Province according to the actual conditions of local climate and soil fertility in Jilin Province. Meanwhile, strengthening the promotion of new varieties in areas with better soil fertility, such as soybean producing areas in central and western Jilin. At the same time, we should popularize the high yield cultivation technology to improve the soybean yield in Jilin Province, and promote the development of soybean industry in Jilin province.

Improving the Level of Mechanization and Promoting the Progress of Soybean Science and Technology. Labor cost of soybean production in Jilin is still high, therefore, it is necessary to improve the mechanization level to realize mechanized operation from soybean cultivation to harvest and field management, and, it is also an important way to improve the yield of soybean in Jilin province. Agricultural Technology in soybean production in Jilin is in a leading position, but, there is still a gap compared with the advanced technology in the world, with the popularization of new varieties and technology, and the improved level of mechanization, the yield of soybean can be improved, so as to better promote the progress of soybean science and technology.

Encouraging Large-scale Production and Reducing Production Costs. The low per unit yield 
of soybean in China is related to the production scale and planting pattern of soybean in China, leading to the yield potential has not been fully played out. Therefore, it is an effective way to reduce the cost and improve the competitiveness of soybean production in Jilin province by encouraging large-scale production of soybean. Combined with the specific situation of soybean in Jilin Province, the large-scale production in soybean production base can be driven by soybean leading enterprises.

\section{References}

[1] X.L.Xu: Study on the development and Countermeasures of soybean production in Jilin [D]. (Ph.D., Jilin Agricultural University, 2006).(In Chinese)

[2] L.M.Luan: An empirical study on soybean production in Jilin [D]. (MS., Jilin Agricultural University, 2011). (In Chinese)

[3] S.Z.Zhu,S.D.Zhou; Study on the elasticity of China's soybean supply response based on extended Nerlove model[J].Soybean science, 2014,05:752-758. (In Chinese)

[4] L.J.Sun:Study on influencing factors and Countermeasures of soybean price fluctuation in Heilongjiang[D].Northeast Agricultural University, 2013. (In Chinese)

[5] D.J.Wang,L.J.Sun: Empirical Analysis on the influencing factors of soybean price fluctuation in Heilongjiang[J].Chinese Agricultural Science Bulletin, 2013,17:217-221. (In Chinese)

[6] L.M.Luan: Analysis of comparative advantage of soybean industry development in Jilin [J].Taxation and economics, 2010, 02: 108-112. (In Chinese)

[7] Z.M.Liu,Y.G.Yang and Z.H.Zhang:The supply and demand characteristics of soybean market in China and the prediction of supply and demand in 2010 - 2020 by Roger Christian curve method[J].Technology and economy, 2010,02:84-88. (In Chinese)

[8] J.F.Liu,H.Q.Zhou and X.Z Li:Analysis on Domestic soybean market price fluctuation and its influencing factors[J].Journal of Northeast Agricultural University (SOCIAL SCIENCE EDITION), 2010,04:10-13. (In Chinese)

[9] Q.L.Jiang: Study on Influencing Factors of soybean sown area in China[D].Nanjing Agricultural University, 2010. (In Chinese)

[10] Y.Gao:Analysis on the influencing factors and changing trend of soybean price in China[J].China agricultural information, 2008,08:43-44. (In Chinese)

[11]H.Liu:Current situation of soybean industry and its exploration in Liaoning[J].Rain fed crops,2007,27(2):155-156 . (In Chinese)

[12] J.A.Zhao:Soybean production and demand situation and development measures in Jilin[J].Agriculture and technology, 2007,10:25 -26. (In Chinese)

[13]Z.X.Zhang:Analysis and Prospect of soybean production and demand in China[J].Agricultural Outlook.2006 (03).13-17. (In Chinese)

[14]Z.M.Li:Analysis on the development and change of soybean production in China[J].Agricultural Outlook.2005(01).18-22. (In Chinese)

[15] Aubert C, X.G.Zhu:Study on soybean economy in China[M].Beijing:China Agriculture Press, 2002:9 - 19. (In Chinese)

[16]A.Z.Yu,C.G.Li:Soybean production in China: Problems and Countermeasures[J].World agriculture.2001 (12).9-11. (In Chinese) 